Medical Center, Bronx, NY. Pre-treatment blood lead levels were $25-55 \mathrm{mcg} / \mathrm{dL}$, and erythrocyte protoporphyrin levels were $>0.65 \mathrm{mcmol} / \mathrm{L}$, in children enrolled. Housing inspections and abatement procedures were performed as necessary, and an iron supplement $(6 \mathrm{mg} / \mathrm{kg}$ day) was prescribed for children (39\% of group) with ferritin levels $<16 \mathrm{mcg} / \mathrm{L}$. Those with positive lead mobilization tests ( $40 \%$ of group) were administered a 5 day course of EDTA. Cognitive development was measured by the Bayley and Stanford-Binet 1) before treatment, 2) at 7 weeks, and 3) 6 months after enrollment. The Stanford cognitive index (CI) increased 1 point for every decrease of $3 \mathrm{mcg} / \mathrm{dL}$ in blood lead level after 6 months but not at 7 weeks after treatment. A moderate correlation of test performance with ferritin levels was the only significant change at short term: every increase of $3 \mathrm{mcg} / \mathrm{L}$ in serum ferritin was associated with an increase of 1 point on the CI. (Ruff HA et al. Declining blood lead levels and cognitive changes in moderately lead-poisoned children. IAMA April 7 1993; 269: 1641-1646). (Reprints: Holly A Ruff PhD, Department of Pediatrics, Room 222, Kennedy Center, Albert Einstein College of Medicine, Bronx, NY 10461).

COMMENT. The results suggest an association between decreases in blood lead level and cognitive improvements in lead-poisoned children. The authors remain cautious in making causal correlations, and they admit a possible contribution of iron supplements or other factors in the cognitive improvements observed.

A study of lead-contaminated soil abatement in Boston and blood lead levels of 152 urban children less than 4 years of age showed that soil abatement around homes results in only a modest decline in blood lead levels ( $2.44 \mathrm{mcg} / \mathrm{dL}$ after an 11 month interval). The median surface soil lead levels were 2075 ppm before abatement and 105 ppm after abatement. Urban children with low-level lead exposure are not appreciably benefited by soil abatement programs. (Weitzman $\mathrm{M}$ et al. IAMA April 7 1993; 269: 1647-1654). An estimated 3 million children in the United States and $69 \%$ of children, 6 months to 5 years of age, in Boston have blood lead levels $>10 \mathrm{mcg} / \mathrm{dL}$, sufficient to impair intelligence and development. (Also see Editorial, Binder S, Matte T, IAMA 1993; 269: 1679).

\title{
ORGANOPHOSPHATE AND DELAYED POLYNEUROPATHY
}

A 3-year-old boy was admitted to the North Shore University Hospital, Manhasset, NY, with acute organophosphate (Dursban) roach poisoning. He was comatose, his pupils were pinpoint, and he had tachycardia, frothy oral secretions, and fasciculations of the eyelids and extremities. Following treatment with atropine and phenytoin, he recovered consciousness and the 
fasciculations ceased. On the 11th day, he developed severe stridor, bilateral vocal cord paralysis, and areflexia with proximal neuropathy. By day 27 , deep tendon reflexes had returned, and EMG and NCS were normal. (Aiuto LA et al. Life-threatening organophosphate-induced delayed polyneuropathy in a child after accidental chlorpyrifos ingestion. I Pediatr April 1993; 122: 658-660). (Reprints: Leslie A Aiuto MD, Div of Pediatric Critical Care Medicine, Dept of Pediatrics, North Shore University Hospital, 300 Community Dr, Manhasset, NY 11030).

COMMENT. Organophosphate-induced delayed polyneuropathy has been described previously only in adults. Clinical manifestations begin 1 to 3 weeks after the acute cholinergic crisis. Signs of a distal, symmetric, motor polyneuropathy may be complicated by pyramidal tract and CNS involvement. Residual deficits are common.

\section{IPECAC-INDUCED NEUROMUSCULAR WEAKNESS}

A 15-month-old girl was admitted to the University of Maryland, Department of Pediatrics, with recurrent vomiting after two previous hospitalizations for vomiting, proximal weakness, and ataxia. Weakness and hypotonia progressed, she could not sit, and deep tendon reflexes were depressed. She was hypotensive, the heart was enlarged, and the pulse rapid. Liver enzymes were markedly elevated. Muscle biopsy was consistent with a myopathy of undetermined cause. By day 12, the endotracheal tube was removed, and by day 14 she could walk. The mother had discovered an empty bottle of ipecac in the infant's toy box some 2 weeks before the initial hospitalization and 4 weeks before the onset of weakness. (Carraccio $C$ et al. Sudden onset of profound weakness in a toddler. I Pediatr April 1993; 122: 663667). (Reprints: Carol Carraccio MD, Dept of Pediatrics, Room N5W56, University of Maryland, 22 S Greene St, Baltimore, MD 21201).

COMMENT. The ipecac poisoning in this case was accidental but is sometimes intentional and a chemical method of child abuse. Emetine produces a neuromuscular weakness of moderate to severe degree by a direct toxic effect on muscle. Cardiomyopathy is an additional side effect of emetine overdose.

\section{INFECTIOUS DISORDERS}

\section{HIV NEUROLOGIC COMPLICATIONS AND HEMOPHILIA}

A multicenter prospective study of the growth and neuropsychological function of 207 boys (mean age 12 years) with hemophilia and seropositive for human immunodeficiency virus type 1 (HIV-1) is reported from the University of Iowa College of Medicine, Iowa City. Head trauma was sustained in $40 \%$, intracranial hemorrhage occurred in $10 \%$, and seizures in $9 \%$. 